\title{
KARAKTERISTIK PERTUMBUHAN DAN HASIL DUA VARIETAS PADI TERCEKAM GARAM NaCl
}

\section{THE GROWTH AND YIELD CHARACTERISTICS OF TWO RICE VARIETIES AFFECTED BY SALT STRESS - NaCl}

\author{
Nasrudin $^{1 *}$, Aditya Wahyudhi ${ }^{2}$ dan Ari Gian ${ }^{1}$ \\ ${ }^{1}$ Fakultas Pertanian, Universitas Perjuangan Tasikmalaya, Tasikmalaya, Indonesia \\ ${ }^{2}$ Program Studi Agronomi, Institut Teknologi dan Sains Nahdlatul Ulama Jambi, Jambi, Indonesia \\ Email: nasrudin@unper.ac.id \\ * Corresponding Author, Diterima: 27 Juli 2021, Direvisi: 16 Des. 2021, Disetujui: 29 Des. 2021
}

\begin{abstract}
Salinity is an abiotic stress that can inhibit the rice growth and production through metabolism disorders. The cultivated rice plants under saline conditions are to know the characteristics of rice variety that can survive to growth and develop optimally. The objective of this research was to examine the growth and yield characteristics of two rice varieties affected by salt stress - $\mathrm{NaCl}$. A factorial completely randomized design was used in this study. The first factor is $\mathrm{NaCl}$ concentration consist of $0 \mathrm{dS} \mathrm{m} \mathrm{m}^{-1}$ and $4 \mathrm{dS} \mathrm{m} \mathrm{m}^{-1}$. The second factor is variety consist of Dendang and IPB 4S. Based on the results of this study shown that Dendang had a higher number of tillers (NoT), root length (RL), number of panicles per clump (NoPC), percentage of filled grain (\%FI), and shoot dry weight (SDW). IPB $4 S$ had a higher plant characteristic. The $0 \mathrm{dS} \mathrm{m-1}$ affected to the number of tillers and root length. Based on the correlation analysis shown that several parameters were positively correlated consists of root length to the number of tillers $(R=0.89)$, shoot dry weight to the number of tillers and root length $(R=0.89 ; R=0.91)$, and the percentage of filled grain to shoot dry weight, root length, number of panicles per clump, and number of tillers $(R=0.87 ; R=0.76 ; R=$ $0.83 ; R=0.89$ ). Variety treatment significantly affected to the growth and yield shown on NoT, $R L, N o P C, \%$ $\mathrm{FI}$, and $\mathrm{SDW}$. While, the $\mathrm{NaCl}$ concentration significantly affected to plant height.
\end{abstract}

Keywords: Morphological characteristic, paddy, production, salinity.

\begin{abstract}
ABSTRAK
Cekaman garam merupakan cekaman abiotik yang mampu menghambat pertumbuhan dan produksi padi melalui mekanisme metabolisme. Usaha yang dapat dilakukan untuk membudidayakan tanaman padi dalam kondisi cekaman garam yaitu mengetahui karakteristik suatu varietas padi agar dapat tumbuh dan berkembang optimal. Tujuan penelitian untuk mengkaji karakteristik pertumbuhan dan hasil dua varietas padi tercekam garam $\mathrm{NaCl}$. Rancangan Acak Lengkap faktorial digunakan dalam penelitian ini. Faktor pertama konsentrasi $\mathrm{NaCl}$ yang terdiri atas dua taraf yaitu $0 \mathrm{dS} \mathrm{m}^{-1} \mathrm{dan} 4 \mathrm{dS} \mathrm{m}^{-1}$. Faktor kedua varietas padi yang terdiri atas dua taraf yaitu varietas Dendang dan varietas IPB 4S. Berdasarkan hasil penelitian menunjukkan bahwa padi varietas Dendang memiliki jumlah anakan (JA), panjang akar (PA), jumlah malai per rumpun (JMpR), persentase gabah isi (GI), dan bobot kering tajuk (BKT) yang lebih besar dibandingkan dengan padi varietas IPB 4S. Namun, padi IPB 4S memiliki karakteristik tanaman yang lebih tinggi dibandingkan padi varietas Dendang. Pemberian konsentrasi $\mathrm{NaCl} 0 \mathrm{dS} \mathrm{m}^{-1}$ menghasilkan jumlah anakan dan akar lebih panjang dibandingkan pemberian konsentrasi $\mathrm{NaCl} 4 \mathrm{dS} \mathrm{m}^{-1}$. Hasil analisis korelasi menunjukkan bahwa beberapa parameter berkorelasi positif, yakni panjang akar terhadap jumlah anakan $(\mathrm{R}=0,89)$, bobot kering tajuk terhadap jumlah anakan dan panjang akar $(R=0,89 ; R=0,91)$, dan persentase gabah isi terhadap bobot kering tajuk, panjang akar, jumlah malai per rumpun, dan jumlah anakan $(R=0,87 ; R=0,76 ; R=0,83 ; R=0,89)$. Penggunaan varietas padi berpengaruh nyata terhadap karakteristik pertumbuhan dan hasil yang terlihat pada parameter JA, PA, JMpR, GI, dan BKT. Sedangkan konsentrasi $\mathrm{NaCl}$ berpengaruh nyata terhadap karakter tinggi tanaman.
\end{abstract}

Kata kunci: Karakter morfologi, padi, produksi, salinitas. 


\section{PENDAHULUAN}

Salinitas merupakan salah satu kondisi lingkungan abiotik yang mampu menghambat pertumbuhan dan menurunkan produksi sebesar 65\% (Ibarra-Villarreal et al., 2021). Salinitas di dalam tanah mampu menyebabkan cekaman pada tanaman seperti cekaman ionik, cekaman osmotik, dan keseimbangan unsur hara (Anshori et al., 2019). Rahman et al., (2016) menyatakan bahwa salinitas menghambat beberapa fase tumbuh tanaman seperti perkecambahan, vegetatif, dan reproduktif.

Menurut Thorat et al., (2018) menyatakan bahwa padi merupakan tanaman yang sangat peka terhadap salinitas dengan konsentrasi mulai $3 \mathrm{dS}$ $\mathrm{m}^{-1}$ sehingga menyebabkan kehilangan hasil sebesar $10 \%$ sedangkan dengan konsentrasi garam sebesar 7,2 dS m ${ }^{-1}$ menyebabkan kehilangan hasil sebesar $50 \%$. Berdasarkan penelitian yang dilakukan oleh Safitri et al., (2017) konsentrasi $\mathrm{NaCl}$ sebesar $120 \mathrm{mM}$ mampu menurunkan pertumbuhan bibit padi hingga menyebabkan kematian dengan waktu 14 hari. Padi varietas Pokkali dan genotipe SAL656 memiliki tingkat ketahanan terhadap salinitas sampai konsentrasi 12 $\mathrm{dS} \mathrm{m}^{-1}$ (Mondal et al., 2013). Berdasarkan penelitian Nasrudin dan Rosmala (2021) padi lokal Tasikmalaya yang berikan cekaman salinitas sampai $8 \mathrm{dS} \mathrm{m}^{-1}$ menyebabkan penurunan terhadap luas daun dan biomasa tanaman, sedangkan ketika diberikan penambahan silika padat akan mempertahankan pertumbuhan tanaman terhadap cekaman salinitas sampai $12 \mathrm{dS} \mathrm{m}^{-1}$ sehingga menghasilkan perbaikan pada luas daun dan laju asimilasi bersih.

Sebagai suatu upaya agar dapat dilakukan budidaya padi pada kondisi salin, maka diperlukan penentuan varietas padi yang akan berpengaruh terhadap toleransinya. Kemampuan setiap tanaman terhadap cekaman salinitas akan berbeda-beda sehingga diperlukan untuk mengetahui karakteristik padi yang akan dikembangkan sebagai upaya penyediaan bahan pangan. Informasi yang diperoleh tentang karakteristik suatu tanaman terhadap cekaman salinitas akan memberikan kemudahan untuk memprediksi keberhasilannya. Padi yang toleran terhadap salinitas memiliki berbagai proses metabolisme yang baik sehingga mampu memberikan pertumbuhan dan perkembangan tanaman yang terbaik. Penelitian ini penting untuk dilakukan guna mendapatkan varietas terbaik yang mampu ditanam pada kondisi salin berdasarkan karakter pertumbuhan dan hasil. Tujuan penelitian ini yaitu untuk mengkaji karakteristik pertumbuhan dan hasil dua varietas padi tercekam garam $(\mathrm{NaCl})$.

\section{BAHAN DAN METODE}

Penelitian dilaksanakan pada bulan Maret sampai Juni 2020 di rumah plastik Program Studi Agroteknologi, Fakultas Pertanian Universitas Perjuangan Tasikmalaya dengan ketinggian tempat 359 mdpl.

Penelitian menggunakan Rancangan Acak Lengkap faktorial. Faktor pertama yakni konsentrasi $\mathrm{NaCl}$ dengan dua taraf $0 \mathrm{dS} \mathrm{m}^{-1}$ dan 4 $\mathrm{dS} \mathrm{m}^{-1}$. Faktor kedua yakni varietas padi dengan dua taraf Dendang dan IPB 4S. Terdapat empat perlakuan dalam penelitian ini, masing-masing kombinasi perlakuan diulang sebanyak tiga kali, dan masing-masing kombinasi perlakuan ditanam sebanyak tiga tanaman sehingga terdapat 36 unit percobaan. Cekaman salinitas menggunakan garam $\mathrm{NaCl}$ yang diberikan saat tanaman berumur 28, 56, dan 77 hari setelah tanam (HST).

Benih padi disemai menggunakan media tanah dan pupuk kandang sapi dengan perbandingan 1:1. Benih padi disemai selama 21 HST, kemudian dilakukan pindah tanam dengan menggunakan media tanam tanah dan pupuk kandang sapi perbandingan 1:1 yang dimasukkan ke dalam polybag berukuran $30 \times 40 \mathrm{~cm}$ dengan bobot $5 \mathrm{~kg}$ polybag $^{-1}$. Pemeliharaan yang dilakukan meliputi pemupukan menggunakan pupuk NPK 16:16:16 dengan dosis $200 \mathrm{~kg} \mathrm{ha}^{-1}$. Pemupukan dilakukan saat tanaman memasuki fase vegetatif awal, vegetatif maksimum, dan memasuki awal fase generatif. Penyiraman/pengairan dilakukan setiap hari menggunakan air sumur. Pengendalian hama dan penyakit dilakukan secara kimiawi menggunakan pestisida berbahan dasar deltametrin dan butyl phenyl methyl carbamate.

Parameter yang diamati meliputi tinggi tanaman (cm) diamati menggunakan alat ukur meteran dengan cara mengukur dari pangkal batang sampai ujung daun tertinggi dan diamati saat tanaman memasuki fase vegetatif maksimum yakni 56 HST. Jumlah anakan diamati berdasarkan anakan yang tumbuh yang dilakukan saat tanaman memasuki fase vegetatif maksimum yakni 56 HST. Panjang akar $(\mathrm{cm})$, bobot kering akar $(\mathrm{g})$, dan bobot kering tajuk (g) diamati menggunakan metode destruktif. Tanaman padi saat berumur 60 HST dicabut seluruh bagiannya sampai pada bagian akar kemudian bagian akar diukur panjangnya 
menggunakan alat ukur meteran untuk mengetahui panjang akar. Tanaman yang telah dicabut kemudian dipisahkan menggunakan alat potong cutter antara bagian akar dan tajuk kemudian dilakukan pengeringan menggunakan oven dengan suhu $80^{\circ} \mathrm{C}$ selama $48 \mathrm{jam}$. Brangkasan yang telah kering kemudian ditimbang menggunakan digital scale dengan akurasi $0,01 \times 5 \mathrm{~kg}$ untuk mengetahui bobot kering tajuk dan bobot kering akar. Persentase gabah isi (\%), jumlah malai per rumpun, dan produktivitas (ton ha ${ }^{-1}$ ) diamati setelah panen. Jumlah malai yang tumbuh per rumpun dihitung secara manual, dalam setiap malai dihitung total seluruh gabah dan jumlah gabah yang isi kemudian dilakukan perhitungan persentase gabah isi, dalam(1). Produktivitas diamati dengan cara mengkonversi bobot gabah per rumpun per satuan hektar.

Persentase gabah isi $(\%)=\frac{\text { jumlah gabah isi }}{\text { total seluruh gabah per malai }} \times 100 \%$ (1)

Data yang diperoleh pada setiap pengamatan dianalisis menggunakan uji $\mathrm{F}$ dan dilanjutkan dengan uji DMRT pada taraf kesalahan 5\%. Perhitungan analisis korelasi menggunakan Pearson correlation untuk mengetahui hubungan antar variabel. Perhitungan analisis statistik menggunakan bantuan software Statistical Tool for Agricultural Research (STAR) versi 2.0.1 dan Microsoft excel.

\section{HASIL DAN PEMBAHASAN}

Pertumbuhan suatu tanaman memiliki keterkaitan dengan produksi yang dapat terlihat melalui beberapa variabel yang diamati dalam suatu penelitian. Tabel 1 menunjukkan bahwa perbedaan varietas berbeda nyata ketika ditanam pada kondisi salinitas. Padi varietas Dendang memiliki jumlah anakan dan bobot kering tajuk yang lebih tinggi dibandingkan dengan padi varietas IPB 4S, namun padi varietas IPB 4 S lebih tinggi dibandingkan dengan padi varietas Dendang. Berdasarkan karakteristiknya, padi varietas Dendang memiliki toleransi yang lebih tinggi terhadap salinitas dan memiliki potensi jumlah anakan sebesar 15 - 20 dibandingkan dengan padi varietas IPB 4S (BB Padi, 2009). Sedangkan padi IPB 4S memiliki karakteristik memiliki tinggi tanaman lebih baik dibandingkan dengan padi varietas IPB 4S, selain itu produktivitas IPB 4S juga lebih tinggi pada kondisi normal dibandingkan dengan Dendang (Rahayu et al., 2020).

Padi yang memiliki toleransi lebih tinggi terhadap kadar garam akan mudah untuk melalukan perbaikan sistem metabolismenya sehingga mampu tumbuh dan berkembang lebih baik. Besarnya bobot kering tajuk pada padi varietas Dendang disebabkan oleh karena hasil asimilasi yang terdistribusikan dengan optimal ke bagian tajuk, selain itu disebabkan juga oleh karena penyerapan unsur hara melalui akar yang lebih baik (Nasrudin dan Kurniasih, 2018). Penyerapan air dan mineral yang optimal akan membantu tanaman dalam perbaikan pertumbuhan pada kondisi salin.

Padi yang ditanam pada konsentrasi garam 0 $\mathrm{dS} \mathrm{m}^{-1}$ memiliki jumlah anakan lebih banyak dibandingkan padi yang ditanam pada konsentrasi garam $4 \mathrm{dS} \mathrm{m}^{-1}$ (Tabel 1). Semakin tinggi konsentrasi garam akan menghambat penyerapan air dan mineral melalui akar. Hal tersebut akan menyebabkan tanaman tidak mampu mendapatkan nutrisi yang cukup untuk mendukung perkembangan tajuk tanaman. Penyerapan air dan mineral terhambat akibat cekaman ionik dan osmotik di dalam sel tanaman. Menurut Munns dan

Tabel 1. Pengaruh Konsentrasi $\mathrm{NaCl}$ terhadap Tinggi Tanaman, Jumlah Anakan, Bobot Kering Tajuk, dan Bobot Kering Akar Dua Varietas Padi.

\begin{tabular}{lcccc}
\hline Perlakuan & $\begin{array}{c}\text { Tinggi tanaman }(\mathrm{cm}) \\
56 \mathrm{HST}\end{array}$ & $\begin{array}{c}\text { Jumlah anakan } \\
56 \mathrm{HST}\end{array}$ & $\begin{array}{c}\text { Bobot kering } \\
\text { tajuk }(\mathrm{g}) \\
60 \mathrm{HST}\end{array}$ & $\begin{array}{c}\text { Bobot kering } \\
\text { akar }(\mathrm{g}) \\
60 \mathrm{HST}\end{array}$ \\
\hline Konsentrasi NaCl & $115,94^{\mathrm{a}}$ & $18,44^{\mathrm{a}}$ & $54,27^{\mathrm{a}}$ & $14,97^{\mathrm{a}}$ \\
$0 \mathrm{dS} \mathrm{m}^{-1}$ & $111,06^{\mathrm{a}}$ & $15,33^{\mathrm{b}}$ & $53,75^{\mathrm{a}}$ & $12,50^{\mathrm{a}}$ \\
$4 \mathrm{dS} \mathrm{m}^{-1}$ & & & & \\
\hline Varietas & $92,78^{\mathrm{q}}$ & $24,28^{\mathrm{p}}$ & $66,37^{\mathrm{p}}$ & $14,45^{\mathrm{p}}$ \\
Dendang & $134,22^{\mathrm{p}}$ & $9,50^{\mathrm{q}}$ & $41,65^{\mathrm{q}}$ & $13,03^{\mathrm{p}}$ \\
IPB 4S & - & - & - & - \\
\hline Interaksi & - & & - & - \\
\hline
\end{tabular}

Keterangan: - (tidak ada interaksi); HST (hari setelah tanam); angka yang diikuti huruf yang berbeda pada kolom yang sama maka berbeda nyata pada Uji DMRT taraf kesalahan 5\%. 
Tester (2008) cekaman osmotik menyebabkan pertumbuhan tajuk baru akan terhambat dan cekaman ionik penyebabkan penuaan dini pada daun. Hal ini akan menurunkan distribusi asimilat sehingga akan menurunkan bobot kering tajuk

Padi varietas Dendang yang ditanam pada konsentrasi garam $0 \mathrm{dS} \mathrm{m}^{-1}$ memiliki akan terpanjang dibandingkan interaksi perlakuan lainnya. Sedangkan padi varietas IPB 4S memiliki akar terpendek pada konsentrasi garam 0 maupun $4 \mathrm{dS}$ $\mathrm{m}^{-1}$. Pemanjangan akar disebabkan kondisi tanaman yang mencari air dan mineral sebagai upaya untuk mempertahankan dirinya. Menurut Gian et al., (2021) menyatakan bahwa akar tanaman padi yang lebih panjang pada kondisi salin sebagai upaya untuk mempertahankan diri dari cekaman ionik dan osmotik untuk tetap dapat menyerap air dan mineral dengan optimal. Hal tersebut akan menunjang pertumbuhan dan perkembangan tanaman. Akar tanaman yang panjang akan menyebabkan peningkatan jumlah malai per rumpun dan bobot kering tajuk tanaman. Hal tersebut tergambar pada hasil analisis korelasi (Tabel 4) yang menunjukkan bahwa panjang akar berkorelasi positif terhadap bobot kering tajuk $(\mathrm{R}=0,91)$ dan jumlah malai per $\operatorname{rumpun}(\mathrm{R}=0,76)$.

Tabel 3 menunjukkan bahwa jumlah malai per rumpun dan persentase gabah isi padi varietas

Tabel 2. Interaksi Konsentrasi $\mathrm{NaCl}$ dan Varietas terhadap Panjang Akar Tanaman Padi.

\begin{tabular}{lccc}
\hline \multirow{2}{*}{ Perlakuan } & \multicolumn{2}{c}{ Konsentrasi NaCl } & \multirow{2}{*}{ Rerata } \\
\cline { 2 - 3 } & $0 \mathrm{dS} \mathrm{m}^{-1}$ & $4 \mathrm{dS} \mathrm{m}^{-1}$ & 39,54 \\
Varietas & $46,21^{\mathrm{aA}}$ & $32,87^{\mathrm{aB}}$ & 24,21 \\
Dendang & $24,18^{\mathrm{bA}}$ & $24,23^{\mathrm{bB}}$ & $31,88(+)$ \\
\hline IPB 4S & 35,19 & 28,56 & \\
\hline Rerata &
\end{tabular}

Keterangan: + (terdapat interaksi); angka yang diikuti oleh huruf yang berbeda pada kolom dan baris yang sama maka berbeda nyata pada uji DMRT taraf kesalahan 5\%. Huruf kecil dibaca ke arah vertical dan huruf kapital dibaca ke arah horizontal.

Tabel 3. Pengaruh Konsentrasi NaCl terhadap Jumlah Malai Per Rumpun, Persentase Gabah Isi, dan Produktivitas Dua Varietas Padi.

\begin{tabular}{lccc}
\hline \multicolumn{1}{c}{ Perlakuan } & Jumlah malai per rumpun & Persentase gabah isi (\%) & Produktivitas (ton ha $\left.\mathrm{a}^{-1}\right)$ \\
\hline Konsentrasi NaCl & & & $1,76^{\mathrm{a}}$ \\
$0 \mathrm{dS} \mathrm{m}^{-1}$ & $15,00^{\mathrm{a}}$ & $38,58^{\mathrm{a}}$ & $1,80^{\mathrm{a}}$ \\
$4 \mathrm{dS} \mathrm{m}^{-1}$ & $14,89^{\mathrm{a}}$ & $34,21^{\mathrm{a}}$ & $1,75^{\mathrm{p}}$ \\
\hline Varietas & & & $1,81^{\mathrm{p}}$ \\
Dendang & $21,00^{\mathrm{p}}$ & $45,95^{\mathrm{p}}$ & - \\
IPB 4S & $8,89^{\mathrm{q}}$ & $26,84^{\mathrm{q}}$ & - \\
\hline Interaksi & - & - &
\end{tabular}

Keterangan: - (tidak ada interaksi); HST (hari setelah tanam); angka yang diikuti huruf yang berbeda pada kolom yang sama maka berbeda nyata pada Uji DMRT taraf kesalahan 5\%.

Tabel 4. Analisis Korelasi pada Berbagai Variabel Pengamatan Menggunakan Pearson Correlation.

\begin{tabular}{lllllllll}
\hline Perlakuan & TT & JA & PA & BKA & BKT & JMPR & \%GI & Provitas \\
\hline TT & $1^{* *}$ & & & & & & & \\
JA & $-0.91^{* *}$ & $1^{* *}$ & & & & & & \\
PA & $-0.74^{* *}$ & $0.89^{* *}$ & $1^{* *}$ & & & & & \\
BKA & $-0.18^{\text {th }}$ & $0.37^{*}$ & $0.35^{*}$ & $1^{* *}$ & & & & \\
BKT & $-0.88^{* *}$ & $0.89^{* *}$ & $0.91^{* *}$ & $0.17^{\text {tn }}$ & $1^{* *}$ & & & \\
JMPR & $-0.84^{* *}$ & $0.84^{* *}$ & $0.76^{* *}$ & $0.19^{\text {tn }}$ & $0.88^{* *}$ & $1^{* *}$ & & \\
\%GI & $-0.75^{* *}$ & $0.79^{* *}$ & $0.77^{* *}$ & $0.04^{\text {tn }}$ & $0.87^{* *}$ & $0.83^{* *}$ & $1^{* *}$ & \\
Provitas & $0.02^{\text {tn }}$ & $-0.05^{\text {th }}$ & $0.09^{\text {tn }}$ & $-0.19^{\text {th }}$ & $0.20^{\text {tn }}$ & $0.25^{*}$ & $0.29^{*}$ & $1^{* *}$ \\
\hline
\end{tabular}

Keterangan: ${ }^{*}$ (terdapat korelasi nyata); ${ }^{* *}$ (terdapat korelasi sangat nyata); ${ }^{\text {th }}$ (tidak terjadi korelasi; TT (tinggi tanaman); JA (jumlah anakan); PA (panjang akar); BKA (bobot kering akar); BKT (bobot kering tajuk); JMPR (jumlah malai per rumpun); \%GI (persentase gabah isi); Provitas (produktivitas). 
Dendang lebih tinggi dibandingkan padi varietas IPB 4S. Jumlah malai per rumpun dipengaruhi oleh jumlah anakan sesuai dengan hasil analisis korelasi dimana jumlah malai per rumpun berkorelasi positif terhadap jumlah anakan $(\mathrm{R}=0,84)$. Hal tersebut menunjukkan bahwa semakin tinggi jumlah anakan akan meningkatkan jumlah malai per rumpun. Selain itu, variabel hasil juga dipengaruhi oleh faktor genetik (Tampoma et al., 2017), secara genetik padi varietas Dendang memiliki jumlah anakan produktif lebih banyak dibandingkan dengan padi varietas IPB 4 S.

Gabah isi yang lebih rendah disebabkan karena kondisi salinitas menyebabkan hambatan dalam perkembangan fase generatif tanaman. Pada fase ini, garam akan menghambat pembuahan dan tanaman akan menghasilkan keterbatasan asimilat. Hal ini menyebabkan banyak gabah menjadi hampa dibandingkan dengan gabah yang terisi. Berdasarkan penelitian Firmansyah (2016) menyatakan bahwa salinitas yang dikombinasikan dengan cekaman genangan mengakibatkan gagalnya pembuahan dan rendahnya distribusi fotosintat menuju gabah. Adapun persentase gabah isi yang lebih tinggi berkorelasi positif dengan jumlah malai per rumpun $(\mathrm{R}=0,83)$. Artinya semakin besar jumlah anakan per rumpun maka akan meningkatkan persentas gabah isi.

Secara umum konsentrasi garam akan mempengaruhi terhadap karakteristik pertumbuhan dan hasil pada tanaman. Tanaman yang memiliki toleransi terhadap salinitas akan dapat beradaptasi dengan baik meskipun beberapa proses metabolismenya tetap terhambat. Oleh sebab itu, dengan mengetahui karakteristik dari suatu tanaman akan memudahkan dalam penentuan varietas yang akan dibudidayakan sehingga tujuan untuk menghasilkan produktivitas yang optimal akan tercapai.

\section{KESIMPULAN}

Berdasarkan hasil penelitian menunjukkan bahwa padi varietas Dendang memiliki karakteristik lebih tahan dibandingkan dengan varietas IPB 4S. Pada varietas Dendang didapat jumlah anakan, panjang akar, jumlah malai per rumpun, persentase gabah isi, dan bobot kering tajuk yang lebih besar dibandingkan dengan padi varietas IPB 4S. Namun, padi IPB 4S memiliki karakteristik tanaman yang lebih tinggi dibandingkan padi varietas Dendang. Pemberian konsentrasi $\mathrm{NaCl} 0 \mathrm{dS} \mathrm{m}^{-1}$ menghasilkan jumlah anakan dan akar lebih panjang dibandingkan pemberian konsentrasi $\mathrm{NaCl} 4 \mathrm{dS} \mathrm{m}^{-1}$. Berdasarkan analisis korelasi menunjukkan bahwa beberapa parameter berkorelasi positif, yakni panjang akar terhadap jumlah anakan $(\mathrm{R}=0,89)$, bobot kering tajuk terhadap jumlah anakan dan panjang akar $(\mathrm{R}=$ $0,89 ; \mathrm{R}=0,91)$, dan persentase gabah isi terhadap jumlah anakan, panjang akar, bobot kering tajuk, dan jumlah malai per rumpun $(\mathrm{R}=0,89 ; \mathrm{R}=0,76$; $\mathrm{R}=0,87 ; \mathrm{R}=0,83$ ).

\section{UCAPAN TERIMA KASIH}

Terima kasih kepada Badan Riset dan Inovasi Nasional yang telah mendukung penelitian ini dengan melalui pembiayaan dana hibah skema Penelitian Dosen Pemula dengan nomor kontrak 080/SP2H/AMD/LT/DRPM/2020 dan 011/SP2H/ AMD/LT-MONO/LL4/2020. Terima kasih juga penulis ucapkan kepada BB Padi yang telah mendukung penelitian ini dengan memberikan benih padi varietas Dendang.

\section{DAFTAR PUSTAKA}

Anshori, M.F., B.S. Purwoko., I.S. Dewi., S.W. Ardie., and W.B. Suwarno. 2019. Selection index based on multivariate analysis for selecting doubled-haploid rice lines in lowland saline prone area. Sabrao Journal of Breeding and Genetics. 51(2): 161-174.

Firmansyah, E. 2016. Tanggapan padi (Oryza sativa L.) terhadap cekaman rendaman dan salinitas (Tesis). Retieved from http:/ /lib.ugm.ac.id/ind/?page_id $=248$.

Gian, A., N. Nasrudin, S. Nurhidayah, and E. Firmansyah. 2021. Pertumbuhan dan hasil padi melalui penambahan hara silika cair pada tingkat cekaman salinitas berbeda. Agrovigor: Jurnal Agroekoteknologi. 14(1): 6-12. Retieved from https://doi.org/ 10.21107/agrovigor.v14i1.8369.

Ibarra-Villarreal, A.L., A. Gándara-Ledezma, A.D. Godoy-Flores, A. Herrera-Sepúlveda, A.M. Díaz-Rodríguez, F.I. Parra-Cota, and S. de los Santos-Villalobos. 2021. Salt-tolerant Bacillus species as a promising strategy to mitigate the salinity stress in wheat (Triticum turgidum subsp. durum). Journal of Arid Environments. 186(2021): 1-8. Retieved from https://doi.org/10.1016/j.jaridenv.2020.104399 Mondal, M.M.A., A.B. Puteh, M.A. Malek, and M.Y. Rafii. 2013. Salinity induced morphophysiological characters and yield attributes 
in rice genotypes. Journal of Food, Agriculture and Environment. 11(2): 610-614.

Munns, R, and M. Tester. 2008. Mechanisms of salinity tolerance. Annual Review of Plant Biology, 59(2008): 651-681. Retieved from Retieved from https://doi.org/10.1146/ annurev.arplant.59.032607.092911

Nasrudin, and B. Kurniasih. 2018. Growth and yield of Inpari 29 rice varieties on raised-bed and different depths of sunken-bed in saline field. Ilmu Pertanian (Agricultural Science). 3(3): 135-145. Retieved from https://doi.org/ 10.22146/ipas. 38736

Nasrudin, N, and A. Rosmala. 2021. Application of silica nutrients to improves local rice productivity under saline conditions. IOP Conference Series: Earth and Environmental Science. 672(1): 1-6. Retieved from https://doi.org/10.1088/17551315/672/1/012006

BB Padi. 2009. Deskripsi varietas padi. In Badan Penelitian dan Pengembangan Pertanian Departemen Pertanian. Balai Besar Penelitian Tanaman Padi, Kementerian Pertanian.

Rahayu, Y., C. Nurjanah, P. Permana, and N. Nasrudin. 2020. Tanggapan ketahanan padi (Oryza sativa L.) varietas IPB 4S terhadap cekaman salinitas dan cekaman genangan selama fase vegetatif awal. AGROSCRIPT: Journal of Applied Agricultural Sciences. 2(1): 56-66. Retieved from https://doi.org/ 10.36423/agroscript.v2i1.527.

Rahman, M.A., M.J. Thomson, M. Shah-E-Alam, M. De Ocampo, J. Egdane, and A.M. Ismail. 2016. Exploring novel genetic sources of salinity tolerance in rice through molecular and physiological characterization. Annals of Botany. 117(6): 1083-1097. Retieved from https://doi.org/10.1093/aob/mcw030.

Safitri, H., B. Sapta, I. Saraswati, and S. Wahyuning. 2017. Salinity tolerance of several rice genotypes at seedling stage. Indonesian Journal of Agricultural Science. 18(2), 63-68.

Tampoma, W.P., T. Nurmala, and M. Rachmadi. 2017. Pengaruh dosis silika terhadap karakter fisiologý dan hasil tanaman padi (Oryza sativa L.) kultivar lokal poso (kultývar 36-Super dan Tagolu). Jurnal Kultivasi. 16(2): 320-325. Retieved from https:// doi.org/10.24198/kultivasi.v16i2.12612.

Thorat, B., T. Bagkar, and S. Raut. 2018. Responses of rice under salinity stress/ : A review. International Journal of Chimical Studies. 6(4): 1441-1447. 